\title{
A vantagem em casa nos jogos desportivos colectivos: revisão da literatura centrada no Basquetebol e no modelo de Courneya e Carron
}

\author{
Jaime Sampaio ${ }^{1}$ \\ Manuel Janeira ${ }^{2}$
}

\author{
${ }^{1}$ Universidade de Trás-os-Montes e Alto Douro \\ Departamento de Desporto \\ Portugal \\ ${ }^{2}$ Universidade do Porto \\ Faculdade de Ciências do Desporto e Educação Física \\ Portugal
}

\begin{abstract}
Home advantage in team sports: a review on Basketball according to the model of Courneya and Carron
\end{abstract}

A vantagem em casa é um dos factores que mais influencia o desfecho final dos jogos de Basquetebol. Neste trabalho, são
identificadas e discutidas questões inerentes às teorias (territorialidade, facilitação social e percepção do apoio social) e aos factores (público, familiaridade com as instalações e viagens) que mais contribuem para este fenómeno. Adicionalmente, apresentam-se os trabalhos disponíveis que estudam os estados psicológicos e comportamentais dos intervenientes no jogo (jogadores, treinadores e árbitros) que surgem, essencialmente, a partir da percepção da vantagem em casa. É dada especial atenção ao conjunto de estatísticas do jogo de Basquetebol que mais distingue a performance das equipas quando jogam em casa, relativamente aos jogos fora. A literatura consultada revelou-nos que a produção científica neste domínio da avaliação da performance das equipas no jogo tem sido frequente. No entanto, apesar de se terem identificado metodologias de análise similares, as estatísticas do jogo, presumivelmente responsáveis pela vantagem em casa, diferem substancialmente em função do contexto particular de cada amostra.

Palavras-chave: vantagem em casa, basquetebol, estatísticas.

\begin{abstract}
Home advantage is one of the most determinant factors in basketball games final outcome. In this review, we identify and discuss questions gathering the theories (territoriality, social facilitation and perceived social support) and game location factors (crowd, facility familiarity and travel effects) that seem to explain home advantage. Additionally, we present the available literature regarding critical psychological and behavioral states in game intervenients (players, coaches and referees) originated by home advantage perception. Our focus is mainly on basketball game statistics that differentiate teams' performance in home and away games. Despite the available quantity, research is not consensual and suggests that these statistics depend upon the context of each analysed sample.
\end{abstract}

Key Words: home advantage, basketball, statistics. 


\section{INTRODUÇÃO}

Nos jogos desportivos colectivos, o conceito de vantagem em casa é representado pela consistência com que as equipas vencem mais de $50 \%$ dos jogos disputados em casa, desde que realizem o mesmo número de jogos em casa e fora, defrontando os mesmos adversários (11). A sua importância e consistência popularizaram-se de tal

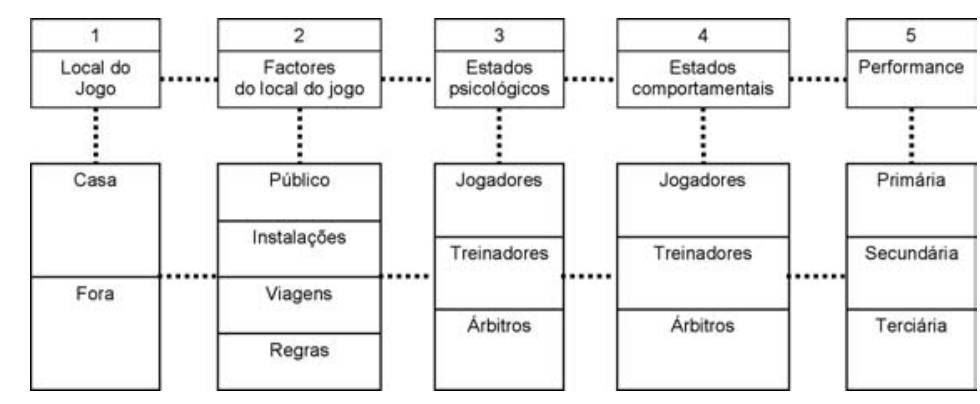
forma que os jornalistas realizam mais referências à dificuldade em vencer a equipa da casa do que a qualquer outro factor (14). De forma bem consensual, a vantagem em casa é um dos factores que mais influenciam o desfecho final das competições desportivas $(11,34,37,52,53,58)$. Contudo, as causas que suportam este facto são ainda pouco conhecidas e exploradas $(5,42)$.

As teorias que procuram dar o melhor enquadramento a este fenómeno baseiam-se em explicações do tipo biológico (e.g., teorias da territorialidade), psicológico-social (e.g., teoria da facilitação social) e cognitivo-social (e.g., teoria da percepção do apoio social). Grosso modo, a ideia subjacente à teoria da territorialidade (3) é a de que os indivíduos se identificam com determinados locais, protegendo-os contra qualquer intrusão. É neste sentido que se considera que a vantagem em casa pode ser um reflexo de defesa de um território muito particular (38). Por outro lado, a teoria da facilitação social $(62,19)$ estuda as alterações de comportamento nas tarefas que são provocadas pela presença de observadores. Nesta situação particular, pretende-se explicar a vantagem em casa pelos efeitos provocados pela presença e participação do público no jogo. Finalmente, a teoria da percepção do apoio social $(13,28)$ aborda este fenómeno a partir das percepções generalizadas de apoio dos indivíduos. Ou seja, o facto de as equipas disputarem os jogos em casa provoca nos indivíduos (jogadores, treinadores,...) uma percepção de apoio social extremamente positiva.

Não existem evidências suficientes na literatura que suportem a utilização exclusiva de alguma destas teorias. Neste sentido e a partir da literatura dispersa, Courneya e Carron (11) construíram um modelo integrativo e estrutural constituído por 5 componentes fortemente inter-relacionadas (ver Figura 1).

Figura 1. Modelo estrutural da investigação centrada na vantagem em casa (adaptado de Courneya e Carron, 11).

Neste modelo, os autores consideram que o estudo do local do jogo implica uma reflexão acerca de quatro factores relevantes para o seu desfecho final (público, instalações, viagens e regras). Por sua vez, estes factores influenciam os estados psicológicos e comportamentais dos jogadores, treinadores e árbitros. Deste modo, as primeiras quatro componentes influenciam directamente a performance ( $5^{\mathrm{a}}$ componente). Por sua vez, a performance é subdividida em medidas primárias, secundárias e terciárias. Nas performances primárias enquadram-se os indicadores que expressam a execução de determinadas acções (e.g., as estatísticas dos jogos), enquanto que as performances secundárias referem-se aos indicadores que decidem o desfecho final dos jogos (e.g., pontos marcados, pontos sofridos). Finalmente, as performances terciárias referem-se às medidas que estabelecem o desfecho final de um jogo (e.g., vitória, derrota). Neste trabalho fica bem vincada a necessidade de se conhecer todas as componentes e todos os factores que favorecem as equipas que jogam em casa em quatro perspectivas fundamentais centradas na (i) associação entre o local do jogo e a performance das equipas, na (ii) influência dos factores do local do jogo no estabelecimento da vantagem em casa, (iii) nos estados psicológicos e (iv) nos estados comportamentais dos jogadores, treinadores e árbitros.

\section{O LOCAL DO JOGO E A PERFORMANCE DAS EQUIPAS}

No Basquetebol, o estudo da associação entre o local do jogo e a performance das equipas tem sido realizado de forma bastante sistemática. Porém, as alterações que se têm verificado nas regras do jogo implicam uma interpretação cuidada e circunstanciada de 
toda a literatura publicada anteriormente a essas alterações. Por exemplo, a inclusão da linha de três pontos no jogo (em 1984) foi uma das alterações à estrutura formal do jogo que mais revolucionou a sua estrutura funcional (16). Neste sentido, é necessário ter algumas precauções na interpretação dos resultados dos estudos que recorreram a amostras anteriores a esta data e nas comparações a efectuar entre os resultados dos estudos disponíveis, relativamente ao conhecimento mais actual do jogo.

Apesar de a literatura identificar o final da década de 1970 e o início da década de 1980 como o momento de arranque da produção de estudos neste âmbito (11), a primeira referência disponível sobre esta matéria data da década de 1950 (23). Hill (23) inquiriu 86 treinadores e verificou que o facto de jogarem em casa permitiu às equipas vencerem mais $33 \%$ dos jogos disputados, comparativamente com as vitórias nos jogos disputados fora, e refere que a vantagem de jogar em casa se situa, em média, nos 7 pontos.

Posteriormente, foi surgindo um conjunto de estudos realizados em diversos contextos que confirmaram a ideia central da existência da vantagem em casa, atribuída ao facto das equipas (i) tentarem e converterem mais lançamentos de campo e lances-livres (com melhores percentagens), (ii) cometerem menos faltas e (iii) conquistarem mais ressaltos $(4,24,50)$. Face a este conjunto de constatações, desde cedo se tem recomendado a realização de sessões de treino no recinto de jogo dos adversários, no sentido de minimizar a vantagem em casa (50).

Em 1977, Barry Schwartz e Stephen Barsky (52) realizaram um estudo que marcou profundamente o conhecimento nesta área de investigação. Os autores recorreram a amostras constituídas por jogos de Basebol, Basquetebol (universitário e profissional), Futebol Americano e Hóquei no Gelo e deixaram bem claro que a vantagem em casa é um facto inegável e presente em todas as modalidades desportivas analisadas. No Basquetebol universitário, as equipas da casa venceram mais $24 \%$ dos jogos disputados. No Basquetebol profissional, a equipa da casa venceu $66,9 \%$ dos 617 jogos do playoff disputados entre 1947 e 1972.

Mais tarde, Varca (58) verificou que as equipas da casa venceram $70 \%$ dos jogos disputados (90 jogos da liga universitária, 1977-1978), como consequência de melhores valores nas bolas recuperadas, ressaltos, desarmes de lançamento e faltas cometidas. Ao longo do tempo, estes resultados foram confirmados por outros autores $(14,18,22,27,39,45,46)$. No final dos anos 80, Silva e Andrew (53) verificaram que o local do jogo afectou significativamente os valores das percentagens de eficácia nos lançamentos de campo, das perdas de bola, das faltas cometidas e dos ressaltos conquistados $(n=420$ jogos, 10 épocas desportivas da NCAA 1971-1981). Os autores pretenderam verificar se as equipas que jogaram em casa expressavam níveis de performance acima da média (vantagem de jogar em casa) ou se, por outro lado, foram as equipas que jogaram fora que expressaram níveis de performance abaixo da média (desvantagem de jogar fora). Da opinião fundamentada dos treinadores foram produzidas as normas de avaliação expressas no quadro 1 .

Quadro 1. Resultados das normas de avaliação obtidas por Silva e Andrew [53] a partir da opinião dos treinadores.

\begin{tabular}{lccc}
\hline Variáveis & Muito Bom & Médio & Fraco \\
\hline Faltas cometidas & $14,4 \pm$ & $15,6 \pm$ & $18,4 \pm$ \\
& 4,96 & 2,42 & 6,50 \\
Percentagem efic. & $51,4 \pm$ & $49,2 \pm$ & $46,0 \pm$ \\
lançamentos de campo & 1,20 & 1,13 & 1,26 \\
Percentagem efic. & $73,8 \pm$ & $70,4 \pm$ & $65,4 \pm$ \\
lances-livres & 1,94 & 0,80 & 0,80 \\
Ressaltos & $37,5 \pm$ & $31,5 \pm$ & $22,5 \pm$ \\
& 2,50 & 3,50 & 2,50 \\
Perdas de bola & $9,8 \pm 1,79$ & $12,5 \pm$ & $15,0 \pm$ \\
& & 1,80 & 2,12 \\
\hline
\end{tabular}

Os valores apresentados são média \pm desvio padrão.

Os resultados evidenciaram que as equipas da casa venceram $65,79 \%$ dos jogos. No quadro 2 , encontram-se as performances das equipas no que concerne às variáveis estudadas. 
Quadro 2. Resultados das performances das equipas nas variáveis estudadas por Silva e Andrew [53].

\begin{tabular}{lccc}
\hline Variáveis & $\begin{array}{c}\text { Jogos em } \\
\text { Casa }\end{array}$ & $\begin{array}{c}\text { Todos os } \\
\text { Jogos }\end{array}$ & $\begin{array}{c}\text { Jogos } \\
\text { Fora }\end{array}$ \\
\hline Faltas cometidas & $19,99 \pm$ & $20,66 \pm$ & $21,32 \pm$ \\
& 2,57 & 2,70 & 2,68 \\
Percentagem efic. & $49,99 \pm$ & $48,86 \pm$ & $47,73 \pm$ \\
lançamentos de campo & 3,67 & 3,87 & 3,75 \\
Percentagem efic. & $71,85 \pm$ & $71,47 \pm$ & $71,08 \pm$ \\
lances-livres & 4,53 & 5,23 & 5,85 \\
Ressaltos & $36,55 \pm$ & $35,36 \pm$ & $34,18 \pm$ \\
& 2,57 & 5,00 & 4,49 \\
Perdas de bola & $15,59 \pm$ & $16,09 \pm$ & $16,58 \pm$ \\
& 2,51 & 2,67 & 2,76 \\
\hline
\end{tabular}

Os valores apresentados são média \pm desvio padrão.

As variáveis foram sujeitas a uma análise discriminante (método stepwise), da qual resultou um compósito linear constituído pelas seguintes estatísticas e respectivas percentagens de explicação da variância do desfecho final dos jogos: ressaltos $(36,5 \%)$, perdas de bola (27,6\%), percentagem de eficácia nos lançamentos de campo $(19,6 \%)$ e faltas cometidas $(16,4 \%)$. Através da comparação dos valores do quadro 1 e do quadro 2 foi possível verificar que: (i) os valores dos ressaltos das equipas que jogaram em casa foram considerados muito bons, enquanto que os das equipas que jogaram fora foram considerados médios; (ii) os valores das percentagens de eficácia nos lançamentos de campo das equipas que jogaram em casa foram considerados médios, enquanto que os das equipas que jogaram fora foram considerados fracos (o que explica as considerações anteriores); (iii) os valores das perdas de bola e das faltas cometidas, de ambas as equipas, foram considerados fracos. Face a este conjunto de resultados foi possível identificar uma "desvantagem de jogar fora" (ao invés da existência da vantagem em casa), estabelecida entre 3 e 5 pontos.

Nos resultados obtidos por Pickens (45), as equipas que jogaram em casa venceram $68 \%$ dos jogos disputados ( $\mathrm{n}=90$ Liga universitária 1990-1991), como consequência de um maior número de assistências e de melhores percentagens de eficácia nos lançamentos de campo (quadro 3). Apesar destas constatações, o autor considera que as estatísticas responsá- veis pela vantagem em casa expressam enormes variações e manifestam-se de uma forma aparentemente aleatória, devido aos seguintes factores: (i) mudanças nas regras do jogo, particularmente a inclusão da linha de $6,25 \mathrm{~m}$ e a forma como actualmente são sancionadas as faltas; (ii) aumento da estatura média dos jogadores, facto que produziu alterações profundas na dinâmica do jogo das equipas; (iii) diferentes "filosofias de jogo" dos treinadores, particularmente centradas em incidências mais ofensivas ou mais defensivas.

Quadro 3. Resultados da comparação de médias das variáveis estudadas por Pickens [45] face ao local do jogo.

\begin{tabular}{lcc}
\hline Variáveis & $\begin{array}{c}\text { Jogos em } \\
\text { Casa }\end{array}$ & Jogos Fora \\
\hline Assistências* & $17,62 \pm$ & $15,55 \pm$ \\
& 4,76 & 4,84 \\
Perc. de eficácia nos lançamentos & $47,53 \pm$ & $45,03 \pm$ \\
de campo* & 6,60 & 6,93 \\
Perc. de eficácia nos lances- & $72,03 \pm$ & $68,16 \pm$ \\
livres & 11,41 & 13,34 \\
Ressaltos & $36,67 \pm$ & $35,12 \pm$ \\
& 8,01 & 6,21 \\
Perdas de bola & $14,31 \pm$ & $15,81 \pm$ \\
& 4,90 & 4,84 \\
\hline
\end{tabular}

Os valores apresentados são média \pm desvio padrão. ${ }^{*} P \leq 0,05$

Uma das questões mais importantes nestes domínios da investigação centra-se na influência do nível de qualidade das equipas sobre a vantagem de jogar em casa $(1,34,52,54)$. Os benefícios de jogar em casa parecem ser mais explorados pelas equipas que, à partida, se consideram de nível superior $(52,54)$. No entanto, na maioria dos estudos, a avaliação do nível de qualidade das equipas foi realizada através da classificação final num campeonato, ou seja, só mede o sucesso das equipas num determinado momento (34). A contrariar esta tendência, Madrigal e James (34) estudaram a influência do local do jogo, em função do nível qualitativo das equipas, através das classificações obtidas ao longo de dez épocas desportivas (entre 1982 e 1992 pertencentes à liga universitária feminina). Os resultados deste estudo evidenciaram o seguinte: (i) nos jogos entre as melhores equipas, a equipa da casa venceu $70 \%$ dos jogos, enquanto que 
nos jogos disputados entre as piores equipas, a equipa da casa apenas venceu $60 \%$ dos confrontos; (ii) quando as melhores equipas defrontaram em casa as piores equipas, venceram $95 \%$ dos jogos. No entanto, a vantagem de jogar em casa também foi igualmente notória nas piores equipas, uma vez que $25 \%$ das suas vitórias ocorreram em casa contra as melhores equipas; (iii) nos jogos disputados em casa, as equipas mais fortes apresentaram melhores valores nas percentagens de eficácia nos lançamentos de campo, roubos de bola e faltas cometidas. Nos jogos disputados em casa, as equipas mais fracas apresentaram piores valores nestas estatísticas do jogo. Não foram identificadas diferenças estatisticamente significativas nos ressaltos conquistados e nas percentagens de eficácia nos lances-livres. Noutra perspectiva, os autores realizaram uma análise de regressão com o objectivo de identificar o contributo da qualidade das equipas, dos factores do local do jogo, das performances passadas e das estatísticas do jogo no seu desfecho final. Este modelo de regressão hierárquica foi constituído pelos seguintes blocos: Bloco 1 - qualidade das equipas, avaliada em função da percentagem de vitórias ao longo das 10 épocas estudadas; Bloco 2 - factores do local do jogo, distância (definida como o número de milhas percorridas pela equipa visitante) e densidade (definida como a relação entre o número de espectadores e a lotação total do recinto de jogo);
Bloco 3 - performances passadas, resultado ao intervalo (medido pela diferença entre os pontos marcados e sofridos) e desfecho do $1^{\circ}$ jogo que opôs as equipas (enquadrado em três categorias: a equipa da casa perdeu o $1^{\circ}$ jogo; venceu o $1^{\circ}$ jogo ou o jogo disputado foi o $1^{\circ}$ da época); Bloco 4 - ressaltos, faltas e roubos de bola. Todas as variáveis foram medidas pela diferença entre as performances da equipa em casa e fora, sempre que defrontou o mesmo adversário; Bloco 5 - percentagens de eficácia nos lançamentos de campo e nos lances-livres. Estas variáveis foram medidas pela diferença entre as performances da equipa em casa e fora, sempre que defrontou o mesmo adversário. O modelo obtido explicou adequadamente a vantagem em casa das equipas (ver quadro 4). O bloco que representa as performances passadas foi o que melhor explicou este fenómeno (36\% da variância). A contribuição individual mais substantiva foi atribuída ao resultado ao intervalo $(\beta=-0,55)$, às percentagens de eficácia nos lançamentos de campo $(\beta=-0,17)$ e aos ressaltos $(\beta=-0,16)$. Como esta análise evidenciou a supremacia clara do resultado ao intervalo, os autores repetiram a regressão excluindo esta variável, de que resultaram contribuições significativas dos roubos de bola e da densidade de espectadores (as vitórias em casa associaram-se a uma maior densidade de espectadores).

Quadro 4. Resultados da regressão hierárquica por blocos realizada por Madrigal e James (34).

\begin{tabular}{|c|c|c|c|c|c|c|}
\hline Bloco & Variável & $\mathrm{R}^{2}$ & $\Delta R^{2}$ & & $\beta$ & \\
\hline 1 & Qualidade & 0,09 & & & $-0,10$ & $P<0,10$ \\
\hline \multirow[t]{3}{*}{2} & Factores do local do jogo & 0,11 & 0,02 & $P<0,05$ & & \\
\hline & Distância & & & & 0,01 & \\
\hline & Densidade & & & & $-0,09$ & \\
\hline \multirow[t]{3}{*}{3} & Performances passadas & 0,48 & 0,36 & $P<0,001$ & & \\
\hline & Resultado ao intervalo & & & & $-0,55$ & $P<0,001$ \\
\hline & Desfecho do $1^{\circ}$ jogo & & & & $-0,01$ & \\
\hline \multirow[t]{4}{*}{4} & Estatísticas do jogol & 0,50 & 0,02 & $P<0,05$ & & \\
\hline & Ressaltos & & & & $-0,16$ & $P<0,01$ \\
\hline & Faltas & & & & 0,08 & \\
\hline & Roubos de bola & & & & $-0,06$ & \\
\hline \multirow[t]{3}{*}{5} & Estatísticas do jogo II & 0,52 & 0,02 & $P<0,05$ & & \\
\hline & $\%$ Lances-livres & & & & $-0,01$ & \\
\hline & \% Lançamentos de campo & & & & $-0,17$ & $P<0,01$ \\
\hline
\end{tabular}


Em jogos pertencentes à fase regular da Liga Profissional de Basquetebol em Portugal ( $n=367$, épocas 1997-1999), Sampaio (49) verificou que as equipas que jogaram em casa realizaram mais assistências e desarmes de lançamento, conseguiram melhores percentagens de jogo (percentagem de posses de bola em que a equipa converteu pontos através de lançamentos de campo de 2 ou 3 pontos) e foram mais eficazes no ataque e na defesa. As equipas que jogaram em casa foram ofensivamente mais eficazes, apesar de terem atingido estes valores superiores de uma forma não padronizada (convertendo, ou mais lançamentos de 2 , ou de 3 pontos ou lanceslivres). Por outro lado, a melhoria da eficácia defensiva foi conseguida através de melhores valores nos desarmes de lançamento. Nos jogos do playoff ( $\mathrm{n}=56$, épocas 1997-1999), o aumento da eficácia ofensiva das equipas que jogaram em casa foi consequência directa de um aumento na conversão de lançamentos de 3 pontos, provavelmente devido à presença de público encorajador (51), à maior familiarização dos jogadores com os aspectos logísticos inerentes ao recinto do jogo (41) e à qualidade das equipas (34).

\section{OS FACTORES DO LOCAL DO JOGO E A VANTAGEM EM CASA}

O contributo dos factores do local do jogo (público, instalações, regras, viagens) na vantagem em casa das equipas tem sido abordado de diversas formas. Os autores têm procurado indagar de que modo o envolvimento criado por cada contexto específico, a partir destes factores, contribui para a vantagem em casa das equipas. Ou seja, o que aqui se pretende é validar uma relação causal (e.g., o aumento da densidade de público provoca um aumento da vantagem em casa). Esta é uma tarefa de difícil resolução, já que obrigaria à manipulação das variáveis a analisar e comprometeria os resultados obtidos $(11,40,41)$, por exemplo, a testagem de uma hipótese que estabeleça uma relação causal entre a performance no jogo e a presença/ausência de público teria que recorrer a uma amostra constituída por jogos disputados na presença e na ausência de público, facto que dificulta a manipulação experimental destas variáveis e, consequentemente, dificulta o seu estudo. Perante estas dificuldades metodológicas, a literatura disponível sobre esta matéria centra-se principalmente em artigos de opinião, estudos inferenciais e estudos de natureza ex-post facto (estudo de situações que ocorreram inadvertidamente e provocaram a manipulação de variáveis).

\section{0 público}

O contributo do apoio do público no aumento da vantagem em casa é tão importante que muitas vezes é designado como o "sexto jogador em campo" (1). De uma forma geral, os resultados da maioria dos estudos disponíveis convergem para a ideia de que o apoio do público afecto à equipa da casa é um factor que influencia positivamente a performance destas equipas $(2,34,35,39,43,50,63)$. O inverso é igualmente verdadeiro, ou seja, as manifestações do público contra a equipa visitante influenciam negativamente a sua performance $(8,56)$. No entanto e apesar da forte tendência evidenciada nos estudos anteriores, existem estudos onde não se identificaram quaisquer diferenças nas estatísticas do jogo causadas pela presença/ausência de público (40). Por outro lado, tem sido apresentada a hipótese da existência de uma desvantagem por jogar em casa (causada pelo público), exclusivamente nos jogos mais decisivos $(6,7,32,33,60,61)$.

Zeller e Jurkovac (63) verificaram que as equipas que jogaram em recintos ao ar livre venceram em casa mais $7,2 \%$ dos jogos $(n=3500$ jogos de Basebol, 17 épocas desportivas). Por outro lado, as equipas que jogaram em recintos fechados venceram em casa mais $10,5 \%$ dos jogos, o que pode sugerir que as diferenças se devem ao efeito provocado pelo apoio do público nos recintos fechados: "Teams perform better and win more games when they receive more enthusiastic crowd support. Since the domed stadium holds the noise ... in the stadium, teams that play under domes ... win more games" (p.20).

No Basebol, Schwartz e Barsky (52) associaram a densidade de espectadores à vantagem em casa $\mathrm{e}$ verificaram que o número de vitórias em casa aumentou de $48 \%$ (com densidades abaixo de 20\%) para $55 \%$ (com densidades entre $20 \%$ e $39,9 \%$ ) e $57 \%$ (com densidades acima dos 39,9\%). Sempre que o nível de qualidade das equipas foi controlado, 
os resultados obtidos não variaram significativamente, facto que poderá ser facilmente explicado pela associação existente entre estas duas variáveis (qualidade das equipas e densidade de espectadores) e à qual Edwards (15) se refere da seguinte forma: "crowds are more dense when the home team is having a winning season, so it is difficult to separate the effects of fan suport from team talent" (p.433).

Thirer e Rampey (56) estudaram o efeito dos comportamentos antisociais do público (“...collective verbal agression, e.g. swearing, chanting obscenities, throwing objects on the court or at each other, and fighting",

p.1048) no número de infracções cometidas (faltas e perdas de bola) em jogos de Basquetebol. Durante os períodos de comportamento normal do público as equipas visitantes cometeram mais infracções, mas durante os períodos de comportamentos antisociais foram as equipas da casa que cometeram mais infracções. Foi possível verificar que esta variação ocorreu pelo aumento das infracções da equipa visitada e não pela diminuição das infracções da equipa visitante, pelo que se sugeriu que os comportamentos antisociais provocam efeitos negativos nas performances das equipas da casa.

Greer (21) procurou verificar o efeito dos períodos de protesto colectivo do público (manifestações ruidosas do público com duração acima de 15 segundos) no número de pontos marcados, de perdas de bola, de faltas e numa estatística de eficácia global. Quando o comportamento do público foi normal, as equipas da casa evidenciaram melhores valores em todas as estatísticas do jogo analisadas. Nos períodos de protesto colectivo, a superioridade foi ainda maior e estatisticamente significativa nos valores das faltas e da eficácia global. Estes resultados podem ser entendidos pelo decréscimo na performance da equipa visitante ou pelos erros na arbitragem decorrentes da intimidação do público (já que a maioria dos períodos de protesto colectivo foi direccionada para os árbitros). Particularmente nos jogos desportivos colectivos, este tipo de comportamentos do público pode afectar negativamente (i) a comunicação entre os atletas das equipas visitantes (por norma, as manifestações do público ocorrem com maior frequência quando a equipa visitante se encontra na fase de ataque), (ii) o timming e a coor- denação das substituições dos jogadores e (iii) a concentração de alguns jogadores (37).

No Futebol, pelo facto dos jogos serem disputados em recintos ao ar livre, onde a influência do público se pode dissipar, o número e a densidade de espectadores não parecem afectar a percentagem de vitórias das equipas da casa $(12,46)$.

Mizruchi (39) procurou associar o desfecho final dos jogos de Basquetebol ao contexto social específico de cada cidade e verificou que os jogos mais difíceis para as equipas visitantes realizaram-se frente a equipas com as seguintes características: “... strong tradition; playing in a city with an intense local identification and pride; and located in a distinctive central city arena" (p. 517).

Em jogos de Hóquei no Gelo ( $n=990)$, Agnew e Carron (2) estudaram o impacto dos factores associados ao público através de um modelo de regressão múltipla que incluiu as seguintes variáveis: (i) número e densidade de espectadores, (ii) período da época e (iii) qualidade do adversário. Os resultados desta regressão atribuíram ao conjunto de variáveis em estudo $1,1 \%$ da variância do desfecho do jogo. A densidade de espectadores foi a única variável que contribuiu significativamente para o desfecho do jogo. Resultados desta dimensão foram igualmente encontrados em jogos de Basquetebol feminino (34). Esta tendência generalizada do aumento da vantagem em casa, a partir do contributo do apoio do público, foi contrariada num trabalho de natureza expost facto (40) que surgiu em virtude do aparecimento de uma epidemia que provocou que 2 equipas universitárias tivessem que disputar 11 jogos na ausência de público. Deste modo, os autores puderam comparar os efeitos do público na performance das equipas, sem a manipulação desta variável. A performance das equipas foi medida através dos pontos marcados e das percentagens de eficácia nos lançamentos de campo e lances-livres.

Como já foi referido, alguns autores têm formulado a hipótese da existência de uma "desvantagem de jogar em casa", exclusivamente, nos jogos mais decisivos $(6,7,32,33,60,61)$. O estudo de referência neste domínio foi realizado por Baumeister e Steinhilber (6) em jogos dos playoff dos campeonatos profissionais norte-americanos de Basebol e 
Basquetebol. No Basebol, as equipas da casa venceram $60,2 \%$ dos primeiros dois jogos das séries, enquanto que no jogo final saíram vencedoras em apenas $40,8 \%$ dos jogos. De um modo semelhante no Basquetebol, as equipas da casa venceram $70,1 \%$ dos primeiros quatro jogos das séries, enquanto que no jogo final saíram vencedoras em apenas $46,3 \%$ dos jogos. Os autores concluíram que a presença de um público apoiante origina determinados estados psicológicos quando surge uma oportunidade para atingir uma identidade muito desejada (e.g., conquistar um campeonato), e que estes estados psicológicos interferem negativamente com as performances dos jogadores nos jogos decisivos. A natureza destes resultados foi posteriormente testada e confirmada no Golf (60) e no Hóquei no Gelo (61).

\section{As instalações}

Os autores identificam como factores influenciadores do desfecho final em jogos de Basquetebol (i) o tamanho dos campos, (ii) a distância entre os limites do campo e as paredes do recinto de jogo e (iii) a iluminação do campo $(11,35,43)$.

Moore e Brylinsky (40) aproveitaram o facto de duas equipas universitárias (uma masculina e uma feminina) terem sido obrigadas a disputar 9 jogos fora do seu recinto habitual para verificarem que a vantagem em casa se manteve. Os autores não consideraram a familiaridade com as instalações como um factor importante para a vantagem em casa e referiram o seguinte: "Our finding that the home advantage persisted in the absence of playing in one familiar facility suggests the plausibility that the home advantage may be influenced most by mental states that cut across players, coaches, officials and the crowd, thus resulting in game performance behavior that is generally more favorable for the home teams than the visiting teams" (p.309).

\section{As viagens}

Os estudos realizados neste domínio pretendem verificar se os factores associados às viagens realizadas pelas equipas visitantes provocam algum tipo de fadiga (física e/ou mental), ou quebram as rotinas diárias dos jogadores, de forma a influenciarem negativamente as suas performances (11). Os resultados disponíveis têm-se mostrado algo contraditórios, alguns autores identificaram fortes associações entre estes factores e o desfecho final dos jogos $(35,54)$ e outros referenciam a ausência de associações desta natureza $(10,15,16,34,44,46,52)$.

Schwartz e Barsky (52) colocaram a hipótese de que o efeito da fadiga e das lesões acumuladas pelos atletas durante os jogos se faria sentir mais pronunciadamente no final dos campeonatos. Deste modo, se os factores associados às viagens fossem importantes, a vantagem em casa seria maior com o decorrer do campeonato, pelo que compararam as percentagens de vitórias das equipas da casa na $1^{\mathrm{a}}$ e na $2^{\mathrm{a}}$ volta (em campeonatos pertencentes a diversas modalidades). Os resultados obtidos e a comparação posterior entre as modalidades estudadas não confirmaram o quadro de hipóteses colocadas - "more time is spent on the road in baseball than in any other sport. Yet, the visitor disadvantage is least pronounced in baseball" (p.650) - confirmadas também por outros autores $(15,46)$.

Pollard (46) recorreu a uma alargada amostra de jogos de Futebol de diferentes épocas desportivas e verificou que em 1932, quando as equipas viajavam sobretudo de comboio (provavelmente as viagens seriam mais fatigantes), a percentagem de vitórias das equipas da casa foi de $54 \%$. Contudo, ao estudar a época de 1952, quando as equipas viajavam sobretudo de avião (provavelmente as viagens seriam menos fatigantes), o autor verificou que a percentagem de vitórias das equipas da casa diminuiu para $52 \%$.

A este tipo de estudos têm sido tecidas algumas críticas (47) centradas no discurso interpretativo dos resultados porque: (i) apesar de actualmente as viagens serem realizadas de forma mais rápida, não existem razões que levem a crer que são menos fatigantes e que quebram as rotinas diárias dos jogadores em menor magnitude; (ii) a comparação entre as percentagens de vitórias das equipas da casa conseguidas na $1^{\mathrm{a}}$ e na $2^{\mathrm{a}}$ volta dos respectivos campeonatos pode não expressar os efeitos da fadiga acumulada, provocada pelas viagens. Muito provavelmente, estes efeitos fazem-se sentir de forma semelhante em todas as equipas.

Courneya e Carron (10) estudaram o impacto dos factores associados às viagens no desfecho final de jogos de Basebol. Através de um modelo de regres- 
são múltipla estudaram: (i) o número da jornada, (ii) a presença de viagem (se a equipa visitada e/ou visitante se deslocaram na noite anterior ao jogo), (iii) o número de jogos em casa consecutivos (em determinados campeonatos as equipas não disputam os jogos em casa/fora alternadamente) e (iv) a distância das viagens realizadas. Os resultados obtidos evidenciaram que este conjunto de variáveis apenas foi responsável por $1 \%$ da variância do desfecho do jogo, tendo as interacções de todas as variáveis explicado somente mais $1,2 \%$ desta variância. Foram obtidos resultados idênticos em amostras de jogos de Hóquei no Gelo (44) e de Basquetebol (34), as variáveis associadas às viagens não contribuíram para explicar a vantagem em casa.

\section{OS FACTORES DO LOCAL DO JOGO E OS ESTADOS PSICOLÓGICOS DOS INTERVENIENTES NO JOGO}

Neste domínio, os autores têm procurado conhecer os factores que os jogadores e treinadores entendem como responsáveis pela vantagem em casa (percepção da vantagem em casa), bem como o grau de importância que estes lhes atribuem.

Jurkovac (26) estudou estas percepções da vantagem em casa a partir da aplicação de um questionário a 74 jogadores de Basquetebol universitário e verificou que os jogadores sentem que jogam melhor perante um público barulhento e activo, quer nos jogos em casa $(97 \%)$, quer nos jogos fora $(74 \%)$. Também foi possível verificar que, nos jogos em casa, os jogadores pensam que as suas estatísticas melhoram (47\%), sentem-se mais confiantes $(76 \%)$ e motivados pelos sinais exteriores de apoio do público presente nos jogos (89\%). Ainda neste estudo, o autor entrevistou 14 jogadores que sugeriram que: $(i) \mathrm{o}$ público funciona como um factor motivacional, transmitindo confiança aos jogadores; (ii) o apoio do público é mais eficaz se for manifestado de forma prolongada; (iii) o jogar em casa é uma pressão adicional para vencer; (iv) os árbitros são mais pressionados pelo público e, consequentemente, mais permissivos com a equipa da casa, facto que permite aos jogadores destas equipas assumirem mais riscos (especialmente em situações da fase defensiva). Thuot et al. (57) estudaram os efeitos da percepção da qualidade do adversário e do local do jogo nos níveis de ansiedade e autoconfiança ( $\mathrm{n}=14$ basquetebolistas masculinos e 9 femininos). As variáveis psicológicas foram medidas 30 minutos antes das competições (Competitive State Anxiety Inventory 2, 36). Foi possível verificar que os jogadores apresentaram níveis mais elevados de ansiedade somática e cognitiva e níveis mais baixos de autoconfiança nos jogos fora. O estudo de Bray e Widmeyer (8) teve como objectivo conhecer a percepção da vantagem em casa numa amostra de basquetebolistas universitárias e verificaram que: (i) as jogadoras sobrestimaram o valor médio da percentagem de vitórias em casa $(60,6 \%$ vs. $55,3 \%$ ), bem como o valor médio da percentagem de vitórias em casa da sua equipa $(59,6 \%$ vs. $54,2 \%)$; (ii) a familiaridade com as instalações do local dos jogos foi identificada por $39 \%$ das jogadoras como o factor mais determinante da vantagem em casa. No entanto, nas respostas obtidas foi identificada, com as instalações do local do jogo, uma sensação de familiaridade geral (definida como "a generalized feeling of familiarity with the venue" p.6, 18\%) e uma específica (definida como "...unique characteristics of their home court such as lighting, rim tension, baskets and boards" p.6, 21\%). Os factores associados ao público e o facto das equipas não realizarem qualquer viagem antes do jogo foram igualmente referidos pelas jogadoras como importantes para as vitórias.

No que concerne à percepção dos treinadores de Basquetebol $(n=15)$ relativamente a estas matérias, o estudo de Fartura (17) revelou que os treinadores consideram que as equipas da casa convertem mais lançamentos de campo e lances-livres, conquistam mais ressaltos ofensivos, roubam mais bolas e sofrem menos faltas. Por outro lado, as equipas visitantes falham mais lançamentos de 2 pontos e lances-livres. As variáveis associadas aos factores do local do jogo consideradas mais importantes foram o pavimento do recinto do jogo, o tipo de tabelas/cestos e a posição dos painéis informativos do (i) resultado do jogo, do (ii) tempo de jogo e (iii) do tempo de posse de bola. Foi ainda salientada pelos treinadores a contribuição positiva da agressividade defensiva das equipas e da participação activa do público. Este conjunto de resultados vem confirmar a importância atribuída às variáveis associadas à familiaridade com as instalações e ao público que assiste aos jogos, já identificadas noutros estudos (48, ver quadro 5). 
Quadro 5. Resultados da opinião dos treinadores no que concerne à importância do público e da familiaridade com as instalações do recinto de jogo no processo de preparação das competições (Sampaio, 48).

\begin{tabular}{ll}
\hline Instalações & Pavimento do recinto de jogo \\
& Tipo de tabelas e cestos \\
& Distância entre os limites do campo e as \\
& paredes do recinto de jogo \\
& Iluminação do recinto de jogo \\
& Climatização do recinto de jogo \\
& Condições dos balneários \\
\hline Público & Tipo de participação do público \\
& Relação entre a produção de jogo da \\
& equipa da casa e as reacções do público \\
\hline
\end{tabular}

\section{OS FACTORES DO LOCAL DO JOGO E OS ESTADOS COMPORTAMENTAIS DOS INTERVENIENTES NO JOGO}

Os estudos deste domínio têm-se centrado nas manifestações de agressividade dos jogadores e nas tomadas de decisão dos árbitros. No primeiro caso, os resultados são muito contraditórios. Alguns autores verificaram que os jogadores das equipas visitadas são mais agressivos do que os jogadores das equipas visitantes $(20,30)$. No entanto, encontramse disponíveis estudos que contradizem esta ideia (52) e outros que não identificam quaisquer diferenças entre os níveis de agressividade dos jogadores das equipas visitantes e visitadas $(38,47)$. Salientese no entanto que McGuire et al. (38), num estudo com jogadores de Hóquei no Gelo, apesar de não terem identificado diferenças na agressividade dos jogadores quando jogam em casa e fora, colocaram a hipótese (mas não a testaram) de as equipas visitadas exibirem níveis de agressividade maiores no início do jogo, enquanto que para as equipas visitantes estes níveis seriam superiores no final do jogo. Esta tendência foi identificada previamente por Widmeyer e Birch (59).

Ainda neste âmbito, Varca (58) considera que os níveis de agressividade dos jogadores não variam em função do local do jogo, i.e., o facto dos jogadores disputarem os jogos em casa ou fora não os torna mais ou menos agressivos. Partindo do princípio que a agressividade pode ser funcional (comportamentos agressivos que aumentam a probabilidade de vencer o jogo) ou disfuncional (comportamentos agressivos que diminuem a probabilidade de vencer o jogo), tem sido possível identificar índices de agressividade funcional superiores nas equipas visitadas - expressos pelos melhores valores nos ressaltos, desarmes de lançamento e roubos de bola - e índices de agressividade disfuncional superiores nas equipas visitantes - expressos pelos piores valores nas faltas cometidas (58). Contudo, este entendimento da agressividade foi alvo de crítica $(11,38)$ em duas questões fundamentais: (i) não é suficientemente claro que as estatísticas apresentadas representem comportamentos agressivos e (ii) o que se considera agressividade deve ser entendido como assertividade.

Esta última questão tem sido bastante debatida pelos psicólogos desportivos (25), no domínio da sua aplicação ao Basquetebol. Lambert (29) diferencia os dois conceitos da seguinte forma: "In today's sports world aggression seems to be the four letter word FOUL. The problem for many of you young players is one of definition because an aggressive basketball player is one who doesn't sit back but takes ACTION. There isn't a coach alive that doesn't want you to be aggressive in this manner. However aggression also has a negative side. What most coaches' desire and call for is really assertiveness although we call is aggressiveness. We even have drills called aggressives...not assertives!

The problem is by definition aggression is an extorted expression of assertiveness. Being aggressive means distorting our physical, social and emotional ability to exert ourselves on the court beyond normal. Unfortunately a great deal of aggressiveness in sports is displaced anger and frustration from factors totally non-related to the sport. Family dysfunction, financial, girlfriend or boyfriend problems, unstable team environment and interaction can all lead to $B A D$ aggression... POSITIVE AGGRESSION or more accurately being assertive as a player. This means that you are able to express and execute your basketball skills in practice or games with confidence and little hesitation at critical times of a game and over the course of a season"( $p .34)$.

Noutra perspectiva, os estudos centrados nas tomadas de decisão dos árbitros em função do local do jogo têm permitido identificar uma tendência de favorecimento das equipas da casa, decorrente da tomada de decisões subjectivas $(20,21,30,55,58)$. No entanto, tem sido salientado que esta tendência pode não ser um indício de más decisões na arbitragem (55), mas ser devida ao facto das equipas visi- 
tantes passarem mais tempo a defender e em desvantagem no resultado. Por outro lado e de certa forma contradizendo estas suposições, foram identificadas diferenças entre a qualidade dos jogadores e o número de faltas que lhes são imputadas nos jogos em casa e fora (31). Mais especificamente, os melhores jogadores cometeram menos faltas em casa do que fora, enquanto que para os piores jogadores não foram identificadas quaisquer diferenças nos dois locais de jogos em referência. Estes resultados podem expressar a reacção dos árbitros perante a pressão do público, a qual consideram que se faz sentir mais pronunciadamente nas acções protagonizadas pelos jogadores mais decisivos (31).

\section{CONSIDERAÇÕES GERAIS}

A influência do local do jogo no seu desfecho final é inequívoca. A produção científica neste domínio revela, de uma forma bem consistente, que a maioria das vitórias das equipas ocorre no seu recinto habitual de jogo. Apesar deste facto, os factores que concorrem para a explicação deste fenómeno parecem pouco consensuais e muito dependentes do contexto específico de cada estudo. No domínio particular do jogo de Basquetebol, apesar de ser possível identificar na literatura revista metodologias de análise quase replicadas, as estatísticas presumivelmente responsáveis pela vantagem em casa diferem de estudo para estudo, pelo que se poderá considerar que são muito circunscritas ao contexto das amostras utilizadas.

\section{CORRESPONDÊNCIA}

Jaime Sampaio

Departamento de Desporto

Universidade de Trás-os-Montes e Alto Douro

Apartado 1013

5000-911 Vila Real

Portugal

ajaime@utad.pt

\section{BIBLIOGRAFIA}

1. Acker J (1997). Location variations in Professional Football. Journal of Sport Behavior 20: 247-259

2. Agnew G, Carron A (1994). Crowd Effects and the Home Advantage. International Journal Sport Psychology 25: 53-62

3. Altman I (1975). The Environment and Social Behaviour: Privacy, Personal Space, Territory. California: Crowding Brooks/Cole Publishing Company

4. Asmussen K (1976). The Relationship of Six Selected Factors to Winning in Basketball. Colorado State University: Unpublished Master Thesis

5. Balmer N, Nevill A, Williams M (2001). Home advantage in the Winter Olympics (1908-1998). Journal of Sports Sciences 19: 129-139

6. Baumeister R, Steinhilber A (1984). Paradoxical Effects of Supportive Audiences on Performance under Pressure: The Home Field Disadvantage in Sports Championships. Journal of Personality and Social Psychology 47: 85-93

7. Baumeister R (1985, April 28). Hometown Fans a Mixed Blessing? Chicago Tribune P D2

8. Bray S, Widmeyer W (2000). Athletes' Perceptions of the Home Advantage: an Investigation of Perceived Causal Factors. Journal of Sport Behavior 23: 1-10

9. Carron A (1988). Group Dynamics in Sport. London: Spodym.

10. Courneya K, Carron A (1991). Effects of Travel and Length of Home Stand/Road Trip on the Home Advantage. Journal of Sport and Exercise Psychology 13: 42-49

11. Courneya K, Carron A (1992). The Home Advantage in Sport Competitions: a Literature Review. Journal of Sport and Exercise Psychology 14: 13-27

12. Dowie J (1982). Why Spain Should Win the World Cup. New Scientist 94: 693-695

13. Dunkel-Schetter C, Bennett T (1990). Differentiating the Cognitive and Behavioral Aspects of Social Support. In: I. Sarason, B. Sarason \& G. Pierce (Eds.) Social Support: an Interactional View. New York: Wiley, 267-296

14. Edwards J, Archambault D (1989). The Homefield Advantage In: J. Goldstein (Ed.) Sports, Games, and Play: Social and Psychological Viewpoints. Hillsdale: Erlbaum, 333-370

15. Edwards J (1979). The Home-Field Advantage In: J. Goldstein (Ed.) Sports, Games, and Play: Social and Psychological Viewpoints. Hillsdale: Erlbaum, 409-438

16. Fajardo, J (1999). Reglamento de Baloncesto Comentado. Barcelona: Paidotribo.

17. Fartura R (2000). O local do jogo como um factor determinante do sucesso em basquetebol. Universidade de Trásos-Montes e Alto Douro: Monografia não publicada

18. Gayton W, Mutrie S, Hearns J (1987). Home Advantage: does it exist in Women's Sports. Perceptual And Motor Skills 65: 653-654

19. Geen R (1989). Alternative Conceptions of Social Facilitation In: P. Paulus (Ed.) Psychology of Group Influence. Hillsdale: Erlbaum, 15-51

20. Glamser F (1990). Contest Location, Player Misconduct, and Race: A Case from English Soccer. Journal of Sport Behavior 13: 41-49

21. Greer D (1983). Spectator Booing and the Home Advantage: a Study of Social Interference in the Basketball Arena. Social Psychology Quarterly 46: 256-261

22. Harville D, Smith M (1994). The Home Court Advantage: 
how Large is it, and does it vary from team to team? The American Statistician 48: 22-31

23. Hill E (1952). Basketball Coaches' Survey. Scholastic Coach, October

24. Hobson H (1955). Scientific Basketball: for Coaches, Players, Officials, Spectators and Sport Writers. Englewood Criffs: Prentice-Hall

25. Husman B, Silva J (1984). Aggression in Sport: definitional and theoretical considerations In: J Silva (Ed.) Psychological Foundations of Sport. Champaign: Human Kinetics, 246-260

26. Jurkovac T (1985). Collegiate Basketball Players' Perceptions of the Home Advantage. Bowling Green Star University: Unpublished Master Thesis

27. Kozub S, Cortlett J (1990). The Home Advantage in Canadian Men's and Women's Basketball. Houston: North American Society for the Psychology of Sport and Physical Activity

28. Lakey B, Drew J (1997). A Social Cognitive Perspective of Social Support In: G. Pierce, B. Lakey, I. Sarason \& B. Sarason (Eds.) Sourcebook of Theory and Research on Social Support and Personality. New York: Plenum, 107-140

29. Lambert A (2002). How to become a more Aggressive (Assertive) Player on the Court: Aggressiveness is a Three-Dimensional Skill. In: A. Lambert Basketball Highway's Playground Pointers: Basic Stuff to Develop Your Game. Monterey: Coacheschoice.

30. Lefebvre L, Passer M (1974). The Effects of Game Location and Importance on Agression in Team Sport. International Journal of Sport Psychology 5: 102-110

31. Lehman D, Reifman A (1987). Spectator Influence on Basketball Officiating. Journal of Social Psychology 127: 673-675

32. Leonard W (1989). The Home Advantage: the Case of the Modem Olympiads. Journal of Sport Behavior 4: 227-241

33. Leonard W (1998). Specification of the Home Advantage the case of the World Series. Journal of Sport Behavior 21: 41-52

34. Madrigal R, James J (1999). Team Quality and the Home Advantage. Journal of Sport Behavior 22: 381-398

35. Maravich P, Belpuliti B (1949). Does the Visiting Team Have a Chance? Athletic Journal. December

36. Martens R, Burton D, Vealey R, Bump L, Smith D (1990). The Competitive State Anxiety Inventory - 2 In: R. Martens, R. Vealey \& D. Burton (Eds.) Competitive Anxiety in Sport. Champaign: Human Kinetics, 117-190

37. McAndrew F (1993). The Home Advantage in Individual Sports. Journal of Sport Psychology 133: 401-403

38. McGuire E, Courneya K, Widmeyer W, Carron A (1992). Aggression as a potential mediator of the Home Advantage in Professional Ice Hockey. Journal of Sport and Exercise Psychology 14: 148-158

39. Mizruchi M (1985). Local Sport Teams and Celebration of Community: a comparative analysis of the Home Advantage. The Sociological Quarterly 26: 507-518

40. Moore J, Brylinsky J (1993). Spectator Effect on Team Performance in College Basketball. Journal of Sport Behavior 16: $77-85$

41. Moore J, Brylinsky J (1995). Facility Familiarity and the Home Advantage. Journal of Sport Behavior 18: 302-311

42. Nevill A, Holder R (1999). Home advantage in sport: an overview of studies on the advantage of playing at home. Sports Medicine 4: 221-236
43. O' Brien J (1951). No place like home. Newsweek February

44. Pace A, Carron A (1992). Travel and the Home Advantage. Canadian Journal of Sport Sciences 17: 60-64

45. Pickens M (1994). Game Location as determinant of team performance in ACC Basketball during 1900-1991. Journal of Sport Behavior 17: 212-217

46. Pollard R (1986). Home Advantage in Soccer: a retrospective analysis. Journal of Sports Sciences 4: 237-248

47. Russell G (1983). Crowd Size and Density in relation to Athletic Aggression and Performance. Journal of Social Behavior and Personality 11: 9-15

48. Sampaio J (1994). O Scouting na Preparação das Competições da Divisão A-1 do Basquetebol Português. UTAD: Monografia não publicada

49. Sampaio J (2000). O poder discriminatório das estatísticas do jogo de basquetebol: novos caminhos metodológicos de análise. Universidade de Trás-os-Montes e Alto Douro: Dissertação de doutoramento não publicada

50. Sanderson D (1969). A Statistical Analysis of the authenticity of the Home Court Advantage Theory In Intercollegiate Basketball. Chico State College: Unpublished Master Thesis

51. Sanna L, Shotland R (1990). Valence of anticipated evaluation and social facilitation. Journal of Experimental and Social Psychology 26: 82-92

52. Schwartz B, Barsky S (1977). The Home Advantage. Social Forces 55: 641-661

53. Silva J, Andrew J (1987). An Analysis of Game Location and Basketball Performance in the Atlantic Coast Conference. International Journal of Sport Psychology 18: 188-204

54. Snyder E, Purdy D (1985). The Home Advantage. Sociology of Sport Journal 2: 352-357

55. Sumner J, Mobley M (1981). Are Cricket Umpires Unbiased? New Scientist 91: 29-31

56. Thirer J, Rampey M (1979). Effects of Abusive Spectator Behavior on the Performance of Home and Visiting Intercollegiate Basketball Teams. Perceptual and Motor Skills 48: 1047-1053

57. Thuot S, Kavouras S, Kenefick R (1998). Effect of Perceived Ability, Game Location, and State Anxiety on Basketball Performance. Journal of Sport Behavior 21: 311-321

58. Varca P (1980). An Analysis of the Home and Away Game Performance of Male College Basketball Teams. Journal of Sport Psychology 2: 245-257

59. Widmeyer W, Birch J (1979). The Relationship Between Aggression and Performance Outcome in Ice Hockey. Canadian Journal of Applied Sport Science 4: 91-94

60. Wright E, Jackson W, Christie S, McGuire G, Wright R (1991). The Home-Course Disadvantage in Golf Championships: Further Evidence for the Undermining Effect of Supportive Audiences on Performance under Pressure. Journal of Sport Behavior 14: 51-60

61. Wright E, Voyer D, Wright R, Roney C (1995). Supporting Audiences and Performances under Pressure: the HomeIce Disadvantage in Hockey Championships. Journal of Sport Behavior 18: 21-28

62. Zajonc R (1965). Social Facilitation. Science 149 : 269-274

63. Zeller R, Jurkovac T (1988, October). Dome-Inating the Game. Psychology Today 20. 